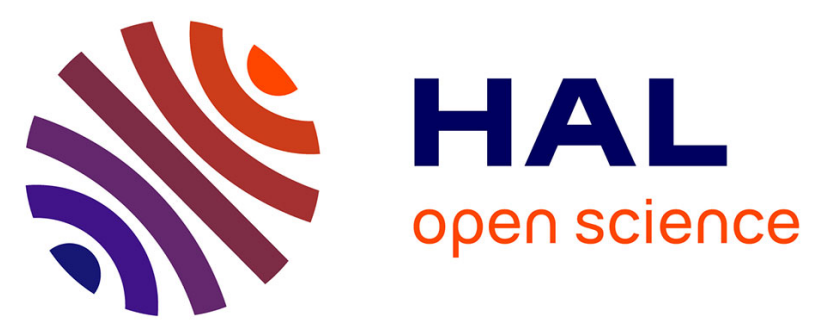

\title{
An Integrated Framework for Simulation and Analysis of Manual Assembly Process
}

Kyung-Hee Lee, Jong Youl Lee, Kyoung-Yun Kim, Sang-Do Noh, Sung-Jun Kang, Doo-Myun Lee

\section{- To cite this version:}

Kyung-Hee Lee, Jong Youl Lee, Kyoung-Yun Kim, Sang-Do Noh, Sung-Jun Kang, et al.. An Integrated Framework for Simulation and Analysis of Manual Assembly Process. 14th IFIP International Conference on Product Lifecycle Management (PLM), Jul 2017, Seville, Spain. pp.162-173, 10.1007/978-3-319-72905-3_15. hal-01764216

\section{HAL Id: hal-01764216 \\ https://hal.inria.fr/hal-01764216}

Submitted on 11 Apr 2018

HAL is a multi-disciplinary open access archive for the deposit and dissemination of scientific research documents, whether they are published or not. The documents may come from teaching and research institutions in France or abroad, or from public or private research centers.
L'archive ouverte pluridisciplinaire HAL, est destinée au dépôt et à la diffusion de documents scientifiques de niveau recherche, publiés ou non, émanant des établissements d'enseignement et de recherche français ou étrangers, des laboratoires publics ou privés. 


\title{
An Integrated Framework for Simulation and Analysis of Manual Assembly Process
}

\author{
Kyung-Hee Lee ${ }^{1}$, Jong Youl Lee ${ }^{2}$, Kyoung-Yun Kim ${ }^{2}$, Sang-Do Noh ${ }^{1 *}$, Sung-Jun \\ $\mathrm{Kang}^{3}$, Doo-Myun Lee ${ }^{3}$ \\ ${ }^{1}$ Dept. of Industrial Engineering, SungKyunKwan University \\ 300 Cheoncheon-dong, Suwon, Gyeonggi-do, 400-746 Korea \\ Tel: 82.31.290.7603, Fax: 82.31.290.7610 \\ Email: \{schnlui. sdnoh\}@skku.edu \\ ${ }^{2}$ Dept. of Industrial and Systems Engineering, Wayne State University \\ 4815 Fourth St., Detroit, MI 48202, USA \\ Tel: 1.313.577.4396, Fax: 1.313.577.8833 \\ Email: \{jong.youl.lee . kykim\}@wayne.edu \\ ${ }^{3} 675-3$ 84B, Gojin-dong \\ Namdong-du, Incheon-si \\ Tel: 82.32.816.8963, Fax: 82.32.819.7939 \\ Email: \{ksj98364002 . ldm\}@segos.com
}

\begin{abstract}
This research aims to build an integrated framework to analyze the production flow efficiency (in terms of worker utilization) of the manual machine component assembly process. Problems related to spontaneous decision making among the workers in the manual assembly processes which cause inconsistency in the manufacturing speed, productivity, and quality. Often it is difficult to simulate all the possible situations to reduce such inconsistencies. This study aims to suggest an alternative way by introducing a prediction framework that is integrated with Modeling and Simulation (M\&S) and a CART algorithm. M\&S is used to create different scenarios out of the original layout for comparison. The CART algorithm is utilized to extract decision rules from the simulation results. These decision rules provide an understanding of patterns that affect workers' utilization rate. The research goal is to adopt the rules on the simulation models, and to offer guidelines on improved alternatives for building simulation models of manual assembly process.
\end{abstract}

Keywords: Manual assembly, modeling and simulation, production flow, integrated simulation, analysis framework, decision rule

\section{Introduction.}

Manufacturing industries, in modern days, have been flourished with advanced technology on robotics and automation in production. However, manual assembly still takes a notable proportion in todays' industries and its manufacturing process. Due to diffi-

adfa, p. 1, 2011.

(C) Springer-Verlag Berlin Heidelberg 2011 
cult assemblage of unevenly shaped parts and the needs of exquisite work, many problems arise from the spontaneous decision making by workers during the assembly process [1]. This problem leads to defective products, irregular quality, fluctuations in productivity and confusion at the work site by the unorganized assembly order. The most prominent problem this research focuses on is the unorganized decision making process among workers on the shop floor. [2]. The current manual assembly process, a worker proceeds defective check by spreading the assembled parts before the next assembly process; however, another worker later also proceeds defective check with the same routine. This overlap of the same process reduces productivity and working speed. To prevent such problems the unnecessary double-check of defectiveness should be avoided. Rather than checking defectiveness on each phase. Checking at the final point of assembly can be one of multiple recommended alternatives. To gauge these problems, this research constructs an integrated decision support framework to analyze the production flow efficiency (in terms of worker utilization) of the manual assembly process. The integrated decision support framework works on the configuration level. An alternative way is by introducing a prediction framework, which is based on the simulation data of the assembly process. A CART algorithm that is utilized to extract decision rules from the QUEST simulation. These decision rules provide an opportunity to understand patterns that effect the workers' utilization rate. With the presented case study, we confirm that the presented framework provides comprehensive understanding of a wide number of variables. From total required time, to inefficient factors such as uneven labor utilization occurred during the manual assembly process. That also reflects those factors to simulation, so that more precise and accurate prediction within the decision making guidelines are enabled on the manual assembly shop floor.

\section{Background}

Shop floor operation can be reconfigured and experimented in practice, however, this can be too expensive, or impractical to do in the system it represents. In a broader sense, simulation is a tool to evaluate the performance of a system, existing or proposed, under different configurations of interest and over long periods of real time [4]. Simulation is defined as techniques of initiating the behavior of a situation or system by means of an analogous situation, model or apparatus, either to gain information conveniently or to personnel [5]. As to evaluate the performance of a system existing or proposed, under different configurations of interest and over long periods of real time. Simulation is the methodology robust enough to systematically examine the role and impact of product complexity and other key variables on factory performance. This is especially true because simulation models can capture many of the requirements and attributes of real life problems that are difficult to consider using analytical model for the layout optimization problems. Computer simulation can provide an operational assessment of the performance objectives and can be examined to see if achieving those objectives is possible through modification to the existing facility.

There are many researches working on solving problems related to manual assembly. Many research suggests Modeling and Simulation (M\&S) as a methodology; however, there is not much progress in adopting more than two research methodology 
with the case. Previous studies mainly focused on variation in productivity due to manual work process design. One of the studies [5] presents an application of simulation modelling within a facility layout of a handwork area. This study is to analyze and optimize the production flow efficiency at the handwork area using QUEST simulation analysis. To address the problem, simulation modelling is employed. Simulation modeling is used in this research since it allows verification of the flow design without having to rearrange the actual physical layout. The outcomes of the simulation model can be used as benchmarks for the efficiency of the new layout. Another study [6] is on problem detection in production lines using simulation. It suggests changing production lines and balancing work efficiency for improving productivity. The study is confined to comparing productivity due to different labor allocation on each machine. Moreover, the study includes manual assembly lines but it only reflects on inefficiency during manual assembly process.

\section{Model Construction for the Integrated Simulation and Analysis Framework}

Before building simulation models. We design a framework for creating simulation models of the manual assembly process. This step is essential since the given manual assembly has many variables related to labors on the shop floor and many decision variables to decide which phase of work to proceed, when to start/switch work and to move the finished parts to the next procedure. The unorganized decision process among labors occurs significantly different work scenarios even though they proceed the same assembly process under the same work manual, and work condition [7].

\subsection{General Model Construction Process}

The general model construction process for modeling $\&$ simulation applied in manual assembly process follows the steps below:

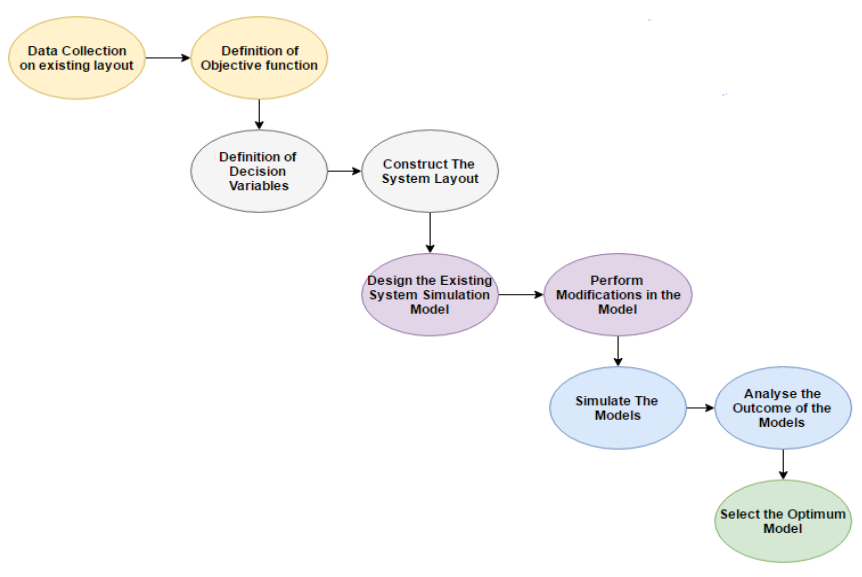

Fig. 1. Process map for shop floor simulation model construction 
1. Define the current system and project objective: one of the objectives of this project is to optimize labor utilization in a manual assembly shop floor. Developing the thought process, we considered the parameters that have some effects on simulation results. The machines used for the assembly procedure were manually operated. Moreover, no automated material handling system was adopted for shop floor logistics, the material movement was performed by the labors using trolleys. As the machines' production rate, material handling time, etc., were all dependent on the labor deployed on each machine, the effect of the labor element on the system got bigger. As the machines' production rate, material handling time, etc., are all dependent to the labor deployed on each machine, the effect of the labor element on the simulation model gets bigger.

2. Data collection: for data collection the known and unknown parameters were specified. The known parameters include the machine and labor specifications, raw material and final product specifications. While the unknown parameters include the utilization time of machines and labors, the idle times for each labor and machines, the average distance travelled by each labor per day.

3. Defining decision variables: the labor utilization parameter depends on the state times (specifically idle time) and the total working time. The objective was not only to increase each labor utilization, but also to have uniform distribution in labor utilization. The total working time for each labor is constant, (10.5 hours in this case), the only variable is the idle time. The idle time of each labor varies with the amount of work allocated to the labor. The more the work, the less the idle time. But this is not always the optimal solution. High utilization of one worker may lead to low utilization of other workers, creating imbalance in the system. Thus, the decision variables were; idle time and labor utilization (percentage as well as its distribution).

4. Pre-requisites for simulation model: before preparing the simulation model, a layout of the existing system was prepared. Which depicted the machine placements, labor placements, the raw material source, finished products sink and buffer storages. A spaghetti diagram was constructed to map the material flow and the labor movement. This layout was then used as a reference to create the simulation model.

5. Preparation of existing system simulation model: the existing system simulation model was constructed. This model generated raw data which was refined and then classified into relevant and non-relevant data. The relevant data in this case was the labor utilization percentage, state times of the each labor, distance travelled by each worker, number of assemblies performed, production rate of the machines. This data was analyzed and the results were documented.

6. Modifying the existing model: the labor utilization was not uniform, thus modifications were performed to improve the existing model. The aim of the modification was to create more simulation models of the system by allocating workers to various tasks, discretely or simultaneously. The labor allocations 
were performed by considering all possible and feasible permutations and combinations.

7. Data analysis: this relevant data was then analyzed and the results were displayed. The models with uniform distribution of utilization were separated. The models with maximum production were selected to be optimal.

\subsection{Simulation Scenario Generation}

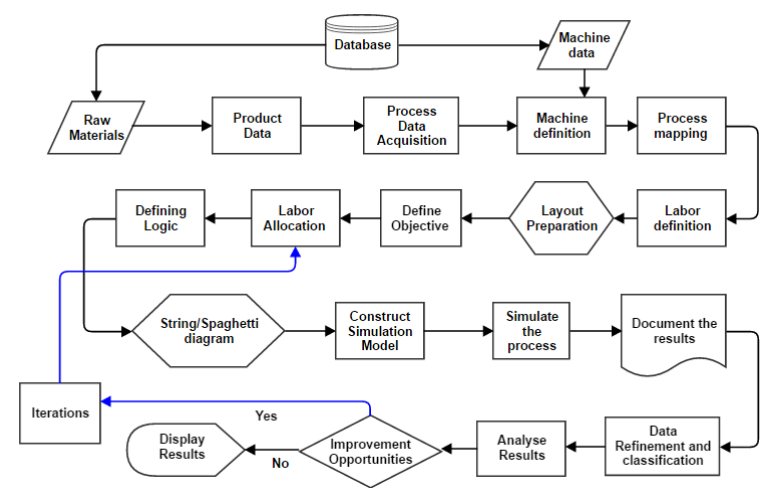

Fig. 2. Simulation scenario generation process

To create meaningful and realistic simulation models, we designed a simulation scenario based on the process as illustrated in Fig. 2. This formal process helps by building simulation scenarios that are based on a previous model. It increases a chance to assuage previous problems and stepping forward to optimal scenario. The algorithm consists of 19 factors.

1. Database contains historical data of machines, parts, raw materials, labor, manufacturing process, etc.

2. Raw Material Data is the information of the raw material for producing the final product such as quantity, dimensions, material type, etc.

3. Machine Data contains information related to machine operation such as cycle time, labor requirement, etc.

4. Product Data contains the information related to the product (assembly or subpart assembly), like, the design, raw material requirement, etc.

5. Process Data contains Information, regarding the process flow, process types in shop floor, labor requirements for each process, rejection rate for each machine.

6. Machine definition provides information about the type of machines used in shop floor, the production rate of each machine, process(es) on each machine, labor specifications for each machine, number of parts processed simultaneously, buffer storage requirements.

7. Process mapping is a schematic representation of the process flow and the 
elements in the process from the beginning to the end.

8. Labor Definition includes the labor parameters such as labor movement speed, rotation speed, number of labor working in shop floor.

9. Layout Preparation refers to the actual machine placement by physical distance between machines, material handling systems (if any), labor placements, buffer stocks, source of raw material, sink of finished products.

10. Labor Allocation refers to Assignments of the labor to respective machine(s). It also assures that every worker is assigned and no worker is free of work.

11. Defining logic is one of the most important element. Logics are specified with which the labor works in the system. Moreover, logics are also specified for the process each machine performs; the logics may include sequence of operation, time offset for a machine to start working, operation time for elements in the system.

12. String/ Spaghetti Diagram represents the material flow in the system. It also depicts the labor movement, amount of rework.

13. Prepare simulation model, Simulation model is the replication of the physical system. Simulation models are useful when testing plans, modifications without physically changing the actual object.

14. Define objectives and specifying objectives is very important to get expected outcome from simulation. The outcomes depend on decision variables due to your objectives.

15. Simulate the process, Each Simulation model will generate data. This obtained data are used as a standard when planning for designing next simulation scenario.

16. Data collection of the raw data is carried out and documented for extracting the specific data.

17. Data refinement \& classification, the data is refined, and those meaningful data are classified according to the objectives. For example, labor utilization, and labor idle time if you are focused on labor efficiency.

18. Result Analysis is conducted to see if there's any hindrance in the production flow and labor utilization. If there is any chance of improvement, the process is iterated by changing the parameters related to the hindrance.

(Refer to Table 2)

19. Display Result records and displays the result which showcases the decision variables, the number of iterations required to attain optimization and the optimization values.

\subsection{CART Algorithm Rule Extraction}

In this paper, we employ a Decision Tree algorithm for data classification and rule extraction from the QUEST simulation dataset. A decision tree is a hierarchical structure of combination of nodes and links. Each node has a predictive condition and a link represents a value of each condition. In our research, Classification and Regression Trees (CART) algorithm is used. The CART is a nonparametric decision tree algorithm 
that used to generate regression tree or classification, depends on whether the response variable is continuous or categorical. By using surrogate splits, CART can handle missing values of the dataset. The data is obtained by the QUEST simulation. The following equation is a basic concept of the CART algorithm.

$$
\mathrm{Y}_{p}=\bar{r}\left(X_{t}\right)=\left[r\left(X_{t}, \lambda, D\right)\right]
$$

where, $\mathrm{Y}_{p}=$ final predicted value, $\bar{r}=$ average regression function, $X_{t}=$ observation from test set, $\lambda=$ random parameter of partition, $D=$ Total data

By using this equation, we made up a model for accurate prediction of the utilization for each labor. $X_{t}$ is the value from the test set which is from dataset $D$. $\lambda$ is a random parameter of partition, which represents $m$ values from the $n$ variables in the test set, where $m<n$. Bootstrap aggregating is a common method in the decision tree that machine learning ensemble meta-algorithm devised to ameliorate both accuracy and stability of the algorithm. A random sample of $m$ predictors is chosen as split candidates from the full set of $n$ predictors while constructing the decision trees. The split should use one of those $m$ predictors. The output of expected values is given as the final predicted value. The predicted value is $\mathrm{Y}$, a leaf node of each branch of the tree. The following section describes a case study and how the simulation data are generated and analyzed with the CART algorithm.

\section{Case study: Slide Rail Assembly Process Simulation and Analysis}

The case study is conducted on the slide rail assembly process. To build simulation models with different scenarios, our research team gathered data for simulation and analyzed present condition of both physical layout of the slide rail assembly line as well as refining the collected data to a certain type of form process flow of slide rail assembly, and process cycle time for building simulation models. The entire assembly process is segmented into modules that have each function on individual levels. By the data collected from the physical slide rail assembly line, a virtual factory similar with the real factory is constructed using QUEST. The simulation model is modified on the module level to create various scenarios on the work shop. The scenarios constructed with this process is used to compare and see if there's any improvement with the modification. In order to generate different scenarios out of the original model, we decided independent variables and dependent variables to thoughtfully compare each model. Independent variables are; simulation time, assembly inputs, pre-set cycle times and layout that are already given. 


\subsection{Slide Rail Manufacturing Shop Floor}

The assembly requires nine steps of the production process in order to produce one finished slide rail. There are twelve workers deployed on the shop floor. While eleven workers assemble the slide rails, the one proceeds sub-part assembly and takes a charge of the shop floor inflow logistics. Each worker decides whether to do inflow logistics, preparation, and packaging in idle time. However, decision making in the manual assembly process based on the worker's subjective observation leads to disorganization, confusion, and fluctuation in both quality and productivity on the work shop.

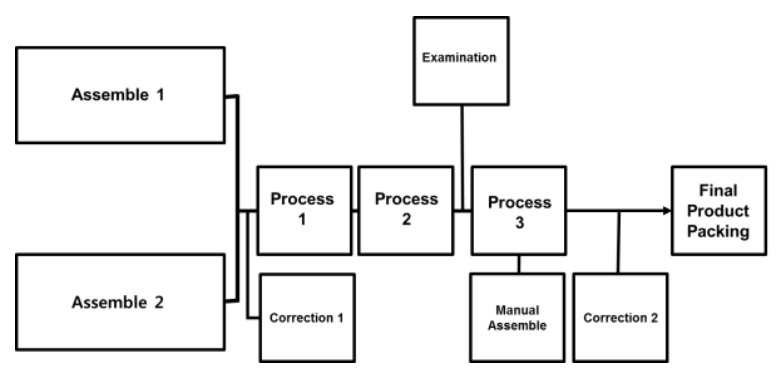

Fig. 3. Process flow of slide rail assembly

In order to organize scenarios in simulation, the process flow is thoughtfully divided into nine main parts as shown on Fig.3. Those segmented module units are analyzed to find out which data should be independent variables and which should be dependent variables. Fig. 4 Shows the virtual model of the shop floor and Table 1 includes the cycle time of the nine phases of the job shop, which is obtained from the QUEST Current Run Summary Report.

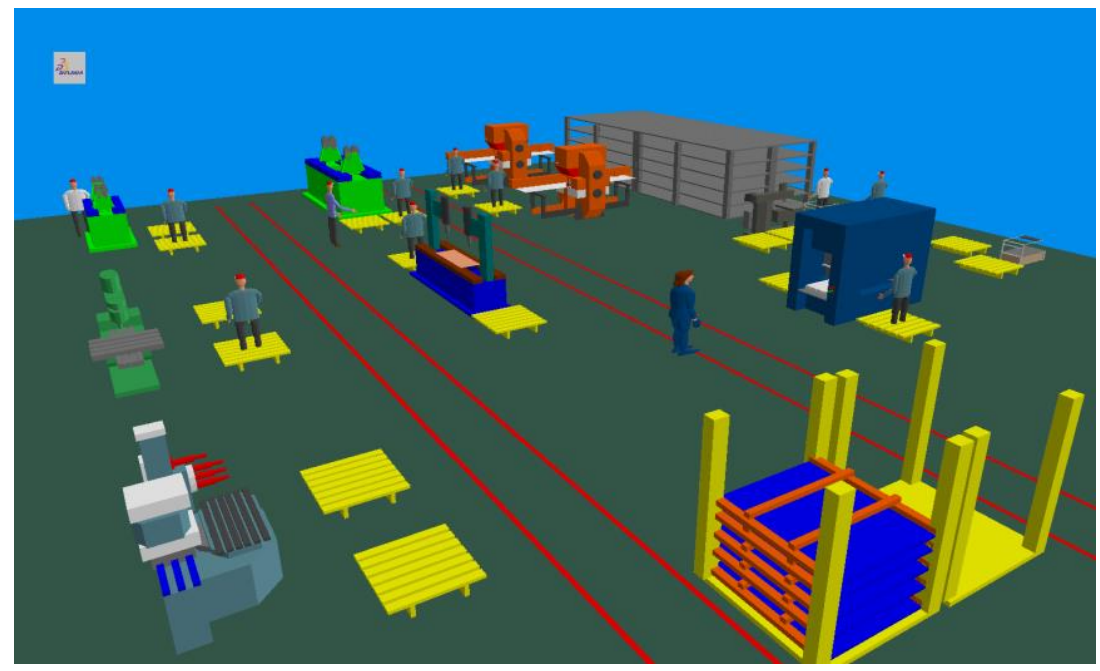

Fig. 4. Virtual model of the shop floor 
Table 1. Cycle time of the slide rail assembly

\begin{tabular}{|c|c|c|c|c|}
\hline & \multicolumn{2}{|c|}{ Phase of Order } & \multicolumn{2}{|c|}{ Cycle Time per unit } \\
\hline \multirow[t]{2}{*}{1} & \multirow[t]{2}{*}{ Part 1 - Part 2} & Pre-work 1 & $8 \mathrm{sec}$ & \multirow[t]{2}{*}{$33 \mathrm{sec}$} \\
\hline & & $\begin{array}{l}\text { Part } 1 \text { - Part } 2 \\
\text { Assembly }\end{array}$ & $25 \mathrm{sec}$ & \\
\hline \multirow[t]{2}{*}{2} & \multirow{2}{*}{ Part 1 - Part 2 - Part 3} & Pre-work 2 & $8 \mathrm{sec}$ & \multirow[t]{2}{*}{$33 \mathrm{sec}$} \\
\hline & & Part 1 - Part 2 - Part 3 Assembly & $25 \mathrm{sec}$ & \\
\hline 3 & \multicolumn{2}{|c|}{ Correction 1} & \multicolumn{2}{|l|}{$20 \mathrm{sec}$} \\
\hline 4 & \multicolumn{2}{|c|}{ Process 1} & \multicolumn{2}{|l|}{$8 \mathrm{sec}$} \\
\hline 5 & \multicolumn{2}{|c|}{ Process 2} & \multicolumn{2}{|l|}{$8 \mathrm{sec}$} \\
\hline 6 & \multicolumn{2}{|c|}{ Examination } & \multicolumn{2}{|l|}{$15 \mathrm{sec}$} \\
\hline 7 & \multicolumn{2}{|c|}{ Process 3} & \multicolumn{2}{|l|}{$25 \mathrm{sec}$} \\
\hline 8 & \multicolumn{2}{|c|}{ Sub-part Assembly } & \multicolumn{2}{|l|}{$12 \mathrm{sec}$} \\
\hline 9 & \multicolumn{2}{|c|}{ Correction 2} & \multicolumn{2}{|l|}{$20 \mathrm{sec}$} \\
\hline
\end{tabular}

\subsection{QUEST Simulation Results}

To get the best result and compare as many scenarios as possible, our research team created 50 different simulation models out of the original model. First, we simulated the original model. In the simulation run report, we found that there are multiple values indicating inefficiencies in the process. For example, we assumed that uneven values in the labor report section refer to unfairly distributed work. By modifying work distribution in the simulation model, we wanted to see if there was any improvement. The 50 simulation models comprehend various scenarios from worker allocation to labor flow pattern. Table 2 is an example of the simulation run report. This table only shows labor analysis section. In Table 2, 'Idle' indicates idle time of each labor allocated in the shop floor and, 'Utilization' indicated how efficiently each labor is used in the whole process. The simulation run report is used to see if there's any hindrance in the current simulation model's production flow and labor utilization. If there is any chance of improvement, the process is iterated by changing the parameters related to the hindrance.

Table 2. Labor analysis by QUEST Current Run Report

\begin{tabular}{|c|c|c|c|c|c|c|}
\hline \multirow[b]{2}{*}{ Name } & \multicolumn{4}{|c|}{ State Times } & \multirow[b]{2}{*}{$\begin{array}{l}\text { Utilization } \\
(\%)\end{array}$} & \multirow[b]{2}{*}{$\begin{array}{l}\text { Distance } \\
\text { Travelled }\end{array}$} \\
\hline & Idle & $\begin{array}{l}\text { Idle - } \\
\text { Parked }\end{array}$ & $\begin{array}{c}\text { Busy - } \\
\text { Loaded } \\
\text { Travel }\end{array}$ & $\begin{array}{l}\text { Busy - } \\
\text { Empty } \\
\text { Travel }\end{array}$ & & \\
\hline Labor1_1 & 0.003 & 6.986 & 1.065 & 2.445 & 33.432 & $15,164,928$ \\
\hline Labor2_1 & 0.02 & 9.219 & 0.631 & 0.631 & 12.016 & $5,450,458$ \\
\hline
\end{tabular}




\begin{tabular}{|c|r|r|r|r|r|r|}
\hline Labor3_1 & 0.019 & 4.033 & 2.725 & 3.723 & 61.412 & $27,856,676$ \\
\hline Labor4_1 & 0.009 & 9.541 & 0.475 & 0.475 & 9.044 & $4,102,443$ \\
\hline Labor5_1 & 0.009 & 9.543 & 0.474 & 0.474 & 9.032 & $4,096,778$ \\
\hline Labor6_1 & 0.02 & 9.332 & 0.574 & 0.574 & 10.935 & $4,960,183$ \\
\hline Labor1_1 & 0.019 & 9.589 & 0.446 & 0.446 & 8.495 & $3,853,170$ \\
\hline Labor8_1 & 0.009 & 9.613 & 0.439 & 0.439 & 8.361 & $3,792,360$ \\
\hline Labor9_1 & 0.009 & 9.532 & 0.479 & 0.479 & 9.129 & $4,140,884$ \\
\hline Labor10_1 & 0.114 & 7.019 & 1.684 & 1.684 & 32.071 & $14,547,564$ \\
\hline Labor11_1 & 0.168 & 5.606 & 2.106 & 2.62 & 45.009 & $20,416,178$ \\
\hline Labor12_1 & 0.327 & 9.336 & 0.418 & 0.418 & 7.969 & $3,614,694$ \\
\hline
\end{tabular}

\subsection{Labor Utilization Prediction and Rule Extraction}

Table. 3 shows the regression rules that are extracted by the Classification and Regression Trees (CART) algorithm. In this study, the CART algorithm is utilized to understand the patterns of factors that affect workers' utilization. Labor utilization is assessed from labor idle, idle-parked, busy-loaded travel, busy empty travel and so forth. The entire assembly process via the equipment and the shop floor logistics are performed by labor. The simulation result elements related to labor, such as machines and parts processed in each phase of the assembly, are affected by the labor utilization. Thus, the shop floor performance (assessed with the elements' utilization, idle, busy-processing, average process time, number of products, average cycle time, production rate, average part residence time etc.) depend on labor utilization. Obtaining evenly distributed labor utilization indicates the entire process is well organized and has less likelihood for having a bottleneck problem.

The parameters of the data are selected from the QUEST simulation dataset based on the potential factors which can affect the utilization of each labor. Those parameters are extracted from machine, labor and sink data, which seems highly related to the utilization of each labor. In the machine data, the following data features are included: 'idle time,' 'busy processing time,' 'blocked unload block time,' 'blocked wait block time,' 'average process time,' 'added parts,' 'the number of products,' 'average cycle time,' 'production rate,' 'average part residence time,' and 'machine utilization'. Also, in the labor data, 'idle time', 'parked idle time', 'busy loaded travel time', 'busy empty travel time', 'the number of parts added', 'distance travelled', and 'utilization of labor'. 'Finished parts' parameter is selected from the sink data. Before implementing the CART algorithm, we clean and find out missing data in the preprocessing step. Then CART is applied to extract the decision rules (i.e., regression trees) for each labor. The objective of the regression model is to minimize Mean Squared Error (MSE) of the model output.

$$
M S E=\frac{1}{n} \sum_{i=1}^{n}\left(y_{i}-f\left(y_{i}\right)\right)^{2}
$$


$y_{i}=$ actual value, $f\left(y_{i}\right)=$ model prediction value, $\mathrm{n}=$ number of observations

Table 3, Shows five extracted decision rule examples, which have relatively low MSE among the twelve labors. Based on the CART result, the rule condition and predicted utilization of each labor is derived. These rules provide various information. For example, the utilization of Labor 2 is related to 'parked idle time' and 'busy loaded travel time'. For Labor 6, it is interesting to know that the utilization of Labor 6 is related to 'busy loaded travel time' of Labor 6, 'parked idle time' of Labor 6, as well as 'parked idle time' of Labor 7. The predicted utilization of selected labors (workers) is also indicated. The right column shows the predicted labor utilization when the corresponding rule condition is satisfied.

Table 3. Rule examples extracted from QUEST simulation

\begin{tabular}{|c|c|c|c|}
\hline $\begin{array}{c}\text { Labor } \\
\text { (Worker) }\end{array}$ & Rule Condition & MSE & Utilization \\
\hline \multirow{3}{*}{1} & $\begin{array}{l}\text { Labor1_1_Busy_Empty Travel }<3.1365 \text {, } \\
\text { Machine10_1_Idle }<5.2265\end{array}$ & \multirow{3}{*}{25.00} & 33.34 \\
\hline & $\begin{array}{l}\text { Labor1_1_Busy_Empty Travel }<3.1365 \text {, } \\
\text { Machine10 } 1 \text { Idle }>5.2265\end{array}$ & & 8.27 \\
\hline & Labor1 1 Busy Empty Travel $>3.1365$ & & 69.81 \\
\hline \multirow{3}{*}{2} & Labor2_1_Idle_Parked $<7.161$ & \multirow{3}{*}{0.22} & 60.33 \\
\hline & $\begin{array}{l}\text { Labor2_1_Idle_Parked }>7.161, \\
\text { Labor2_1_Busy_Loaded Travel }>0.8675\end{array}$ & & 26.22 \\
\hline & $\begin{array}{l}\text { Labor2_1_Idle_Parked }>7.161, \\
\text { Labor2_1_Busy_Loaded Travel }<0.8675\end{array}$ & & 12.02 \\
\hline \multirow{3}{*}{4} & $\begin{array}{l}\text { Labor4_1_Busy_Loaded Travel }<1.443 \text {, } \\
\text { Labor4_1_Idle_Parked }<3.8435\end{array}$ & \multirow{3}{*}{16.804} & 0.00 \\
\hline & $\begin{array}{l}\text { Labor4_1_Busy_Loaded Travel }<1.443 \text {, } \\
\text { Labor4_1_Idle_Parked }>3.8435\end{array}$ & & 10.42 \\
\hline & Labor4_1_Busy_Loaded Travel $>1.443$ & & 62.65 \\
\hline \multirow{4}{*}{6} & $\begin{array}{l}\text { Labor6_1_Busy_Loaded Travel }<0.786 \text {, } \\
\text { Labor6_1_Idle_Parked }<9.1425\end{array}$ & \multirow{4}{*}{19.067} & 1.594 \\
\hline & $\begin{array}{l}\text { Labor6_1_Busy_Loaded Travel }<0.786 \text {, } \\
\text { Labor6_1_Idle_Parked }>9.1425\end{array}$ & & 10.630 \\
\hline & $\begin{array}{l}\text { Labor6_1_Busy_Loaded Travel }>0.786 \text {, } \\
\text { Labor7 1 Idle Parked }<7.7495\end{array}$ & & 26.620 \\
\hline & $\begin{array}{l}\text { Labor6_1_Busy_Loaded Travel }>0.786 \text {, } \\
\text { Labor7_1_Idle_Parked }>7.7495\end{array}$ & & 46.390 \\
\hline \multirow{4}{*}{12} & $\begin{array}{l}\text { Labor12_1_Idle_Parked Travel }<7.8025, \\
\text { Labor12_1_Idle_Parked }<7.144\end{array}$ & \multirow{4}{*}{1.96} & 36.320 \\
\hline & $\begin{array}{l}\text { Labor12_1_Idle_Parked Travel }<7.8025 \text {, } \\
\text { Labor12_1_Idle_Parked }>7.144\end{array}$ & & 27.950 \\
\hline & $\begin{array}{l}\text { Labor12_1_Idle_Parked Travel }>7.8025, \\
\text { Labor12_1_Busy_Loaded Travel }<0.637\end{array}$ & & 7.937 \\
\hline & $\begin{array}{l}\text { Labor12_1_Idle_Parked Travel }>7.8025, \\
\text { Labor12_1_Busy_Loaded Travel }<0.637\end{array}$ & & 18.070 \\
\hline
\end{tabular}




\section{Conclusions}

This paper presents a concept of the integrated simulation and analysis framework for slide rail assembly process. Simulation model construction and scenario generation process were used to analyze the manual assembly process and productivity. The QUEST simulation provided a comprehensive analysis of labor utilization. The CART analysis from the QUEST Current Run Report enhanced the simulation by providing the prediction capability and rule pattern analysis. In the future research, the team will continue to validate the prediction algorithm to enhance with random forest algorithm. Also, the framework concept will be implemented as a unified modeling and simulation research environment.

\section{Acknowledgement.}

This research was supported by grants from BK21 Research \& HRD Team for Smart Factory Design, Operation and Optimization based on Industrial Data Analytics (Program No.: 22A20154613485), and WC300 Project for Smart Rail \& Smart Manufacturing System Development (Program No.: S2367439). These supports are gratefully acknowledged.

\section{References.}

1. Bäckstrand, G., De Vin, L. J., Högberg, D., \& Case, K. (2006). Attention, interpreting, decision-making and acting in manual assembly. Innovations in Manufacturing.

2. Gonzalez, C., Lerch, J. F., \& Lebiere, C. (2003). Instance-based learning in dynamic decision making. Cognitive Science, 27(4), 591-635.

3. Frazzon, E. M., Albrecht, A., \& Hurtado, P. A. (2016). Simulation-based optimization for the integrated scheduling of production and logistic systems. IFACPapersOnLine, 49(12), 1050-1055.

4. Maria, A. (1997, December). Introduction to modeling and simulation. In Proceedings of the 29th conference on Winter simulation (pp. 7-13). IEEE Computer Society.

5. Alia, M., Omara, A. R., Samana, A. M., Othmanb, I., Halima, I., \& Rahima, A. H. (2010). QUEST® SIMULATION ANALYSIS FOR FACILITY LAYOUT REDESIGN OF HANDWORK AREA.

6. Young-Su Yun. (2008).An Methodology for Improving Worker Utilization and Productivity of Part Assembly Line by 3D Simulation Analysis. In Review of business \& economics, 21(6), 2803-2822.

7. Battini, D., Faccio, M., Persona, A., \& Sgarbossa, F. (2011). New methodological framework to improve productivity and ergonomics in assembly system design. International Journal of industrial ergonomics, 41(1), 30-42. 